J. Amer. Soc. Hort. ScI. 127(5):814-818. 2002.

\title{
A Mild Systemic Reaction to Lettuce Mosaic Virus in Lettuce: Inheritance and Interaction with an Allele for Resistance
}

\author{
Edward J. Ryder \\ US Department of Agriculture, Agricultural Research Service, 1636 East Alisal Street, Salinas, CA 93905
}

\begin{abstract}
Aditional INDEX WORDs. stem lettuce, plant introduction, markers, breeding, Lactuca sativa
Abstract. In crosses of lettuce (Lactuca sativa L.) between parents producing a mild or susceptible reaction to lettuce mosaic virus, a single gene segregated. The heterozygote reacted in an intermediate manner. In crosses between mildreacting and resistant parents, the mild reaction gene and the resistant gene segregated independently. The resistant and mild alleles together produced a new phenotype that is usually symptomless. The gene symbol proposed is $M i$ 'Mi, where $M i$ ' gives the mild phenotype. Breeding is in progress to combine the mild and resistant traits in new lettuce cultivars.
\end{abstract}

Lettuce mosaic has been a serious worldwide disease problem in lettuce (Lactuca sativa L.), and a few other leafy vegetable species, for a long time. It was first identified as a virus (LMV) disease by Jagger (1921). It can be seriously debilitating, causing losses of up to $100 \%$, especially in production districts like the Salinas Valley of California, where the disease can be transmitted from older to younger crops throughout most or all of a long growing season, primarily by the green peach aphid (Myzus persicae Sulz.). Two methods of control have been developed: 1) use of resistant cultivars and 2) seed indexing and use of seed stocks virtually free of the virus (Grogan, 1980; Ryder, 1975). Both methods of control have been effective.

This paper describes a gene controlling the type of reaction to lettuce mosaic virus (LMV) in the lettuce plant. A susceptible plant reacts systemically, manifesting vein clearing, mottling, leaf recurving, leaf margin frilling, distortion, stunting, and occasional necrosis. Resistance is also manifested systemically with one or a few small chlorotic areas on veins or vein junctions and considerably less stunting. The term resistance is used in a generic sense; a more precise and descriptive term is resistance to virus increase and spread (Bjorling, 1966). The mild reaction discussed in this paper is also systemic, but with milder effects, such as less obvious mottling, less leaf distortion, and less stunting, as compared to the susceptible reaction.

\section{Materials and Methods}

Eight accessions were used in various crosses. They react differently to LMV and included two cultivars, two stem lettuces from Egypt, a Plant Introduction accession from Egypt, and three derived genetic lines (Table 1). A total of seven crosses were studied: 'Balady Aswan Green' (BAG) (mild) x 'Salinas' (severe), BAG X 'Salinas 88' (resistant), BAG x PI 251245 (resistant), BAG x 'Balady Aswan Red' (BAR) (resistant), G-14-2 X BAG, G-5-1 x BAG, and BAG $\times$ G-14-3. The stem lettuce arrived from Egypt in a single package labeled 'Balady Aswan'. It was a mixture producing either red or green plants. The red group may have the same resistance allele as PI 251245, an oilseed lettuce, which was our original source of resistance used in the breeding program. The numbered lines in the last three crosses were selected for study because they appeared to have a higher level of resistance to the virus.

Received for publication 28 Jan. 2002. Accepted for publication 5 June 2002. This work was supported in part by the California Lettuce Research Board. Thanks to David J. Milligan for technical assistance.
All studies were conducted in a greenhouse. Seed was sown in flats or plastic pots in a sand-soil mixture. Plants were inoculated in the seed containers at the three- to four-leaf stage. The virus used was originally collected from a single plant in a lettuce field in the Salinas Valley in 1958. It has been maintained by plant to plant transfer and is available. No detectable change has been noted. The vector was the green peach aphid, cultured on a long white radish, transferred to LMV infected lettuce plants, and then to healthy seedlings. Symptoms were read at 12 to $14 \mathrm{~d}$ and $21 \mathrm{~d}$ or more, depending upon the reaction expected. The numbers of plants showing each type of reaction were recorded and the data were analyzed by chi-square.

An additional experiment was carried out to clarify the results obtained in the inheritance studies. Four genotypes with different levels of resistance were compared in a nonreplicated experiment for percent infection and days to first symptom expression.

\section{Results}

The $F_{1}$ of BAG $x$ 'Salinas' showed severe symptoms. Two $F_{2}$ populations were grown. The first (93-713) was observed only for mild versus severe symptom expression (Table 2). However, intermediate symptom expression could often be distinguished from mild and severe, and the second population (94-431) was observed for all three phenotypes (Table 2). In this and other populations, plants with intermediate expression were sometimes difficult to separate from those classified as either mild or severe. Therefore two classes have been combined, usually intermediate with mild, occasionally intermediate with severe, depending upon overall severity of symptom expression, which in turn depended on light and temperature conditions at the time of the experiment. Segregation in population 93-713 approached 3 mild : 1 severe and in population 94-431 approached 1 mild : 2

Table 1. Parents used in crosses described.

\begin{tabular}{lll}
\hline \hline Parent & Type & LMV reaction \\
\hline Salinas & Crisphead & Severe \\
Salinas 88 & Crisphead & Resistant \\
Balady Aswan Green (BAG) & Egyptian stem & Mild \\
Balady Aswan Red (BAR) & Egyptian stem & Resistant \\
PI 251245 & Oilseed & Resistant \\
$90-210-G-5-1$ & $\mathrm{~F}_{3}$ plant & Symptomless \\
$90-210-$ G-14-2 & $\mathrm{F}_{3}$ plant & Symptomless \\
$90-210-$ G-14-3 & $\mathrm{F}_{3}$ plant & Symptomless \\
\hline
\end{tabular}


Table 2. Segregation (Seg) of lettuce mosaic reaction types in cross Balady Aswan Green X 'Salinas'. Mild (M) class may include intermediate (I) plants; $\mathrm{S}=$ severe.

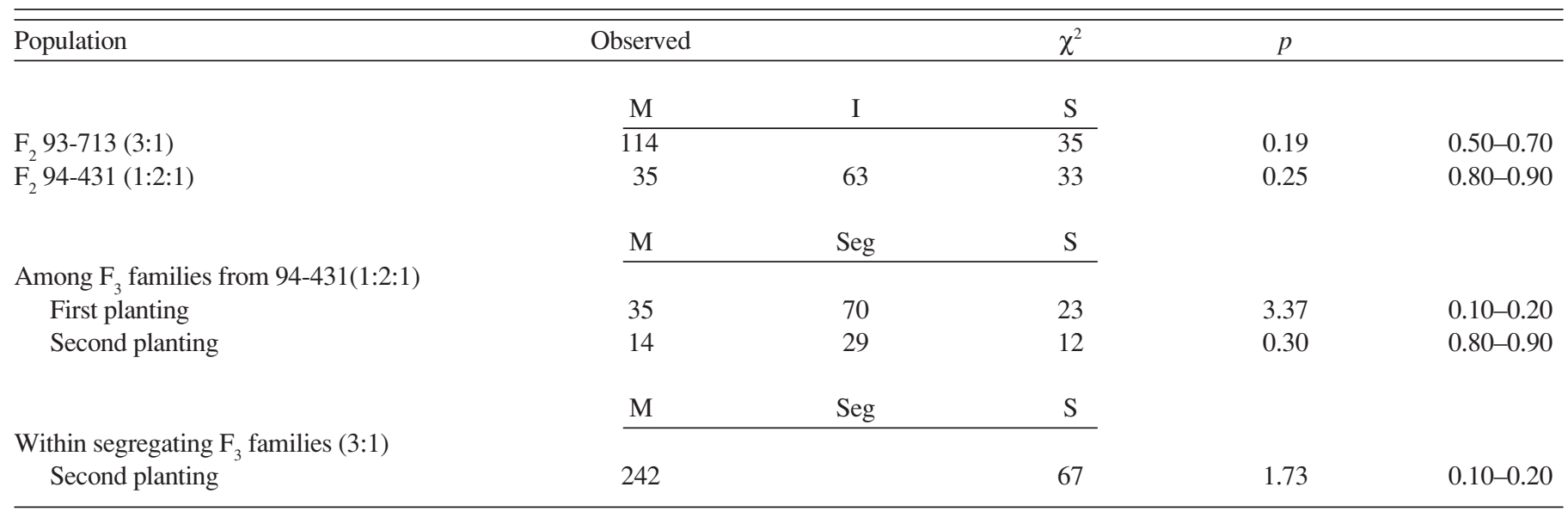

Table 3. Segregation in $\mathrm{F}_{2}$ populations of lettuce mosaic reaction types in crosses between mild (M) and resistant (R) parents. Mild class may include intermediate (I) plants; $\mathrm{S}=$ severe.

\begin{tabular}{|c|c|c|c|c|c|c|c|}
\hline \multirow[b]{2}{*}{ Population } & \multicolumn{5}{|c|}{ Observed } & \multirow[b]{2}{*}{$\chi^{2}$} & \multirow[b]{2}{*}{$p$} \\
\hline & $\mathrm{M}$ & $\mathrm{I}$ & $\mathrm{S}$ & NS & $\mathrm{R}$ & & \\
\hline \multicolumn{8}{|c|}{ BAG x Salinas $88(93-712,3: 6: 3: 3: 1 ; 94-430,9: 3: 3: 1))$} \\
\hline $94-430$ & 82 & & 24 & 32 & 4 & 4.10 & $0.20-0.30$ \\
\hline \multicolumn{8}{|c|}{ BAG x PI 251245 (9:3:3:1) } \\
\hline $90-210$ & 106 & & 38 & 34 & 13 & 0.35 & $0.95-0.98$ \\
\hline $95-936(2)$ & 23 & 49 & 21 & 19 & 4 & 2.61 & $0.50-0.70$ \\
\hline \multicolumn{8}{|l|}{ Sums } \\
\hline 9:3:3:1 & 188 & & 62 & 66 & 17 & 1.09 & $0.70-0.80$ \\
\hline $3: 6: 3: 3: 1$ & 71 & 129 & 62 & 71 & 20 & 1.20 & $0.80-0.90$ \\
\hline
\end{tabular}

Table 4. Segregation among $\mathrm{F}_{3}$ families of lettuce mosaic reaction types in crosses between mild and resistant parents. Mild class includes intermediate plants.

\begin{tabular}{|c|c|c|c|c|c|c|c|c|}
\hline \multirow[b]{2}{*}{ Class $^{\mathrm{z}}$} & \multicolumn{2}{|c|}{$90-210$} & \multicolumn{2}{|c|}{$95-936(1)$} & \multicolumn{2}{|c|}{$95-936(2)$} & \multicolumn{2}{|c|}{ Total } \\
\hline & No. & $\chi^{2}$ & No. & $\chi^{2}$ & No. & $\chi^{2}$ & No. & $\chi^{2}$ \\
\hline$\overline{\text { All M }}$ & 3 & 0.28 & 7 & 1.39 & 4 & 0.63 & 14 & 0.02 \\
\hline All NS & 2 & 1.05 & 5 & 0.06 & 6 & 0.00 & 13 & 0.16 \\
\hline$M: S$ & 12 & 1.84 & 12 & 1.00 & 19 & 4.27 & 43 & 6.76 \\
\hline Like $F_{2}$ & 21 & 1.39 & 18 & 0 & 19 & 0.95 & 58 & 0 \\
\hline$S: R$ & 0 & 8.13 & 2 & 5.44 & 8 & 1.27 & 10 & 12.44 \\
\hline All R & 1 & 2.31 & 8 & 2.72 & 5 & 0.15 & 14 & 0.02 \\
\hline Total & 65 & 26.45 & 72 & 12.22 & 95 & 8.28 & 232 & 22.76 \\
\hline$P$ & & $<0.01$ & & $0.10-0.20$ & & $0.30-0.50$ & & $<0.01$ \\
\hline
\end{tabular}

${ }^{\mathrm{z}} \mathrm{M}=$ mild, NS = symptomless, $\mathrm{S}=$ severe, $\mathrm{R}=$ resistant.

intermediate : 1 severe. Two populations of $\mathrm{F}_{3}$ families were grown from $F_{2}$ plants of the 94-431 population. Segregation among families approached 1 all mild : 2 segregating : 1 all severe (Table 2). Within segregating $\mathrm{F}_{3}$ families, segregation approximated 3 mild and intermediate : 1 severe. These results indicate a single gene for LMV reaction. Expression of dominance appears to be dependent upon the conditions under which the segregating population is grown.

Three sets of populations were studied in which the cross was between BAG and a resistant parent : BAG x 'Salinas 88', BAG $x$ PI 251245, and BAG x BAR. 'Salinas 88' and PI 251245 have the same allele for resistance (mo-1mo- 1 ). Because BAR and PI 251245 are both of Egyptian origin, and a cross between the two shows no segregation, it is likely that BAR also has the same allele. However, the identity of the alleles would not affect segregation ratios.

Two $\mathrm{F}_{2}$ populations of BAG x 'Salinas 88 ' were studied. In the first (93-712), in addition to the mild and resistant phenotypes, the 
Table 5. Segregation within segregating $\mathrm{F}_{3}$ families of lettuce mosaic reaction types in crosses between mild (M) and resistant (R) parents. Mild class includes intermediate plants; $\mathrm{S}=$ severe.

\begin{tabular}{|c|c|c|c|c|c|c|}
\hline Class & \multicolumn{4}{|c|}{ Observed } & $\chi^{2}$ & $p$ \\
\hline \multicolumn{7}{|c|}{ Group 95-936(1) (3:1 or 9:3:3:1) } \\
\hline$M: S$ & 176 & 54 & & & 0.28 & $0.50-0.70$ \\
\hline $\mathrm{M}: \mathrm{S}: \mathrm{NS}: \mathrm{R}$ & 241 & 86 & 138 & 26 & 28.53 & $<0.01$ \\
\hline NS : R & & & 73 & 11 & 6.35 & $0.01-0.02$ \\
\hline $\mathrm{M}: \mathrm{NS}$ & 114 & & 41 & & 0.17 & $0.50-0.70$ \\
\hline$M: S$ & 143 & 62 & & & 3.00 & $0.05-0.10$ \\
\hline $\mathrm{M}: \mathrm{S}: \mathrm{NS}: \mathrm{R}$ & 115 & 47 & 36 & 17 & 2.80 & $0.30-0.50$ \\
\hline NS : R & & & 88 & 37 & 1.41 & $0.20-0.30$ \\
\hline $\mathrm{S}: \mathrm{R}$ & & 30 & & 10 & 0 & $>0.99$ \\
\hline
\end{tabular}

Table 6. Segregation (Seg.) of lettuce mosaic reaction types in crosses between symptomless (NS) and mild (M) parents.

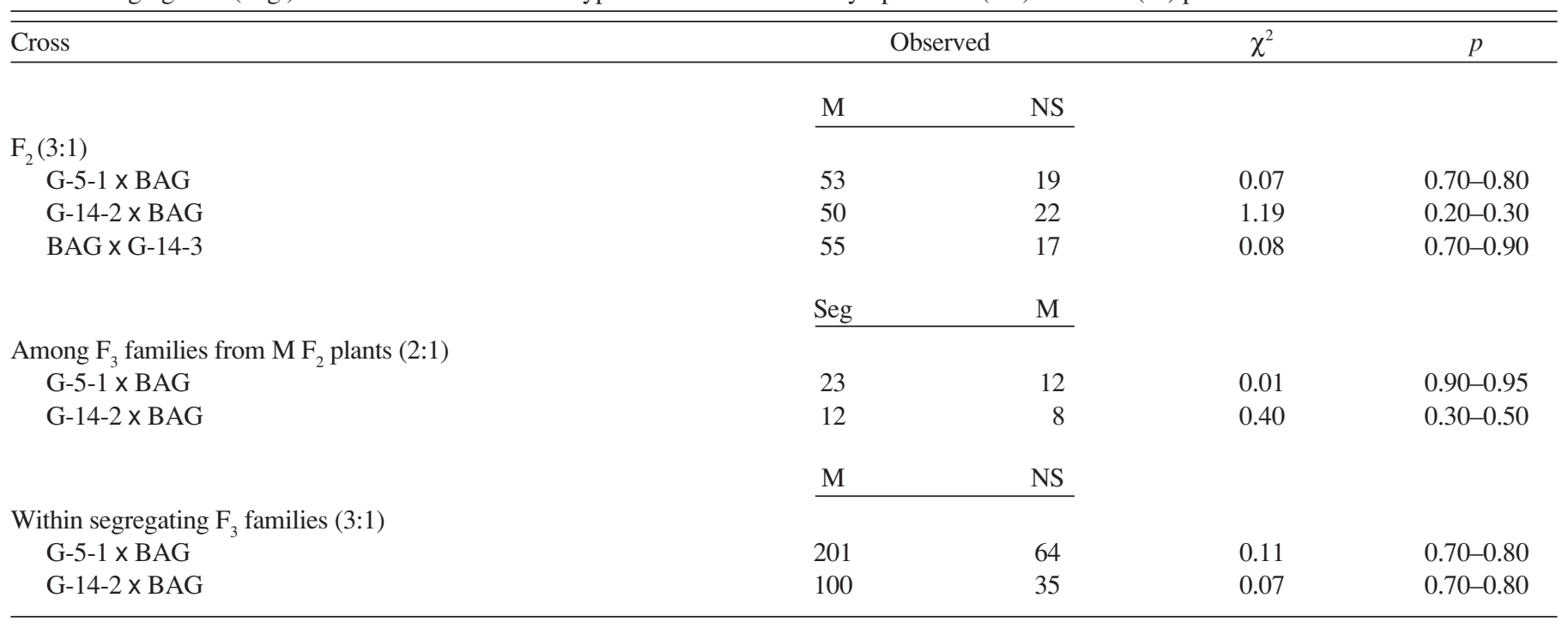

severe and intermediate reaction types also appeared and were distinguishable from each other. Also a new phenotype-no symptom (NS)_appeared. I postulated that these plants were either escapes or resulted from the combination of the allele for resistance and an allele for mild reaction. $\mathrm{F}_{2}$ segregation gave a poor fit to 3 mild : 6 intermediate : 3 severe : 3 NS : 1 resistant (Table 3 ). The NS class had an excess number of plants, suggesting the class included escapes. The second population was scored for four classes, and approximated 9 mild (plus intermediate) $: 3$ severe : 3 NS : 1 resistant, suggesting two genes. $F_{3}$ families were not examined.

The $\mathrm{F}_{2}$ of BAG $x$ PI 251245 (90-210) segregated $\approx 9$ mild : 3 severe : $3 \mathrm{NS}: 1$ resistant (Table 3 ). Two $\mathrm{F}_{2}$ populations from the cross BAG $x$ BAR (95-936) were grown and were $\approx 3$ mild : 6 intermediate : 3 severe : $3 \mathrm{NS}: 1$ resistant. Combining the data for $\mathrm{F}_{2}$ populations segregating into four or five classes results in good fits to $9: 3: 3: 1$ or $3: 6: 3: 3: 1$ ratios. The action of two genes, with one allelic combination giving a high level of resistance, is strongly suggested.

$\mathrm{F}_{3}$ families were investigated for the crosses of BAG with PI 251245 and BAR. The difficulty of obtaining consistent distinction of the intermediate phenotype from mild and/or severe and of the NS phenotype from escapes, as well as the need for large populations to properly identify families segregating for both genes, made the analysis difficult and required repeated regrowth of various family groups. The expected phenotypic classes are 1 all mild; 2 mild : NS; 1 all NS; 2 mild : severe; 4 like the $\mathrm{F}_{2} ; 2$ NS : resistant; 1 all severe; 2 severe : resistant; 1 all resistant. The mild class includes intermediate reaction plants.

The ratio of phenotypic classes among $\mathrm{F}_{3}$ families from the cross BAG X PI 251245 (90-210) is shown in Table 4. The fit to the expected ratio is very poor. Several difficulties are apparent, especially the number of families, which is far too low for the expected number of classes. Also the total number of families for the all severe and severe : resistant classes is low. Those classes are progenies of severe $\mathrm{F}_{2}$ plants, which were severely damaged by the virus and produced few or no seeds. The result was a reduced number of families in these classes.

The ratio of phenotypic classes among $\mathrm{F}_{3}$ families from the cross BAG $\times$ BAR is also shown in Table $4 . \mathrm{F}_{3}$ family sets were grown from both $\mathrm{F}_{2}$ populations (95-936). In each family group, the fit to the expected ratio is acceptable. However, if the numbers in each class for 90-210 and both 95-936 populations are summed, the overall fit to the expected ratio is poor, due primarily to a shortage of families in the classes derived from severe $\mathrm{F}_{2}$ plants, especially in the severe : resistant class. Removal of the severe 
Table 7. Comparison of four reaction genotypes (G-5-1, highly resistant; BAR, resistant; BAG, mild; Salinas, susceptible) in six experiments for proportion of plants showing symptoms and mean number of days to symptom expression.

\begin{tabular}{|c|c|c|c|c|}
\hline Entry & G-5-1 & BAR & BAG & Salinas \\
\hline \multicolumn{5}{|l|}{ Inoculated 19 Dec. } \\
\hline No. plants & 24 & 26 & 29 & 30 \\
\hline Percent infected & 45.8 & 61.5 & 89.7 & 100 \\
\hline \multicolumn{5}{|l|}{ Inoculated $20 \mathrm{Feb}$. } \\
\hline No. plants & 12 & 12 & 12 & 12 \\
\hline Percent infected & 58.3 & 91.7 & 83.3 & 83.3 \\
\hline \multicolumn{5}{|l|}{ Inoculated 6 Mar. } \\
\hline No. plants & 12 & 12 & 12 & 12 \\
\hline Percent infected & 58.3 & 100 & 100 & 91.7 \\
\hline Days to symptom & 30.1 & 17.5 & 13.6 & 10.3 \\
\hline \multicolumn{5}{|l|}{ Inoculated 20 Mar. } \\
\hline No. plants & 12 & 12 & 12 & 12 \\
\hline Percent infected & 20.0 & 80.0 & 89.7 & 83.3 \\
\hline Days to symptom & 29.0 & 18.5 & 13.8 & 10.8 \\
\hline \multicolumn{5}{|l|}{ Inoculated 21 August } \\
\hline No. plants & 12 & 12 & 11 & 12 \\
\hline Percent infected & 8 & 50.0 & 100 & 83.3 \\
\hline Days to symptom & 34 & 29.0 & 13.5 & 8.3 \\
\hline
\end{tabular}

and severe : resistant classes from the overall calculation gives $\chi^{2}$ $=6.06, \mathrm{p}=0.30-0.50$.

Ratios within segregating $\mathrm{F}_{3}$ classes should be the same as single gene or two gene $\mathrm{F}_{2}$ ratios. However, many families included unresolved NS plants, which could have been escapes or actual NS plants. It was therefore difficult to make accurate counts within some families. Counts were made within families segregating mild : resistant; mild : severe; mild plus intermediate : severe : NS : resistant; NS : resistant; and severe : resistant for both 95-936 populations (Table 5). Expectations were for 3:1 and 9:3:3:1 ratios. In the 95-936(1) group, segregation within NS : resistant families and mild : severe : NS : resistant families did not meet expectations and in both cases can be attributed to probable escapes included in the NS class. Removal of five families in which the number of NS plants exceeded the number of mild plus intermediate plants resulted in a considerably better $\chi^{2}=0.66, p$ $=0.80-0.90$. In the 95-936(2) group, all five family sets met expectations.

Three plants in two $\mathrm{NS} \mathrm{F}_{3}$ families from BAG x PI 251245 were crossed with BAG: G-5-1 x BAG, G-14-2 x BAG, and BAG X G-14-3. $F_{1}$ plants showed mild symptoms. $F_{2}$ populations segregated mild : NS, approximating a 3:1 ratio (Table 6). Segregation among $\mathrm{F}_{3}$ families from mild $\mathrm{F}_{2}$ plants approximated a ratio of 2 segregating : 1 all mild. Within segregating families, segregation approximated 3 mild : 1 NS (Table 6).

In the inheritance studies described, most plants in the NS class did not show symptoms of lettuce mosaic when inoculated; a few plants showed a chlorotic lesion, similar to that exhibited by resistant plants, but expressed at a later time. This phenomenon required further investigation.

A series of experiments were run to quantify the difference between the resistant types and those showing no symptom expression. I compared G-5-1, BAG, BAR, and 'Salinas' in six plantings for percent of plants showing symptoms and days to symptom expression. The first planting was inoculated on 19 December; the sixth was inoculated on 21 August. Reactions could then be tracked in winter, spring, and summer.

Differences in symptom frequency and time of appearance are related to reaction type and season (Table 7). Plants designated NS may not have been symptom free, but fewer plants showed symptoms and they took longer to express symptoms than resistant plants. The infection rate decreased rapidly as the days got longer and warmer. In the midsummer planting, all plants but one of G-5-1 were symptomless. Most plantings for the inheritance studies described were planted in late spring, summer, and early fall so that nearly all highly resistant plants were in fact NS. Nevertheless, the designation highly resistant appears to be more appropriate than NS. Resistant plants were less likely to express symptoms than mild and susceptible plants, and took longer to express symptoms. Mild and susceptible plants were similar in both traits, although susceptible plants usually showed symptoms earlier.

In three of the experiments, two other symptomless lines were also tested and reacted similarly to G-5-1, suggesting little or no phenotypic variation in that group.

\section{Discussion}

Despite some poor segregation ratios, these results show that the mild reaction is controlled by a single gene, with alleles for mild and severe reactions; the heterozygote is intermediate. In the mild $x$ severe crosses, a single gene segregates, suggesting that both parents are $\mathrm{Mo}-1 \mathrm{Mo}-1$, i.e. susceptible. The crosses between mild and resistant parents indicate that two genes are segregating, one for mild versus severe and one for susceptible versus resistant. The latter must be Mo-1mo-1. In the mild x NS crosses, both 
parents have the mild allele, and the $\mathrm{Mo}-1 \mathrm{mo}-1$ gene is segregating. Therefore, the combination of mild and resistant produces the highly resistant phenotype. The mild versus severe gene is labeled $M i ' M i$, with $M i$ ' conferring the mild reaction, and $M i$ conferring severe (susceptible). Highly resistant plants must be Mi' Mi'mo-1mo-1.

Resistance breeding programs have been based upon the use of one or the other of two alleles for resistance. These were originally designated $g g$ (Bannerot et al., 1969) and momo (Ryder, 1970), but were later shown to be allelic (Dinant and Lot, 1992). The alleles are hereby designated $m o-l^{g}$ and $m o-l^{e}$, respectively ( $g$ refers to the source cultivar Gallega and $e$ to Egypt, source of the Plant Introduction lines containing that allele). These designations are consistent with published rules for lettuce genes, and should replace previously used numerical superscripts (Robinson et al., 1983).

The results of this work suggest further studies. One is an investigation of the heterozygote, $M i$ ' $M i$, and its phenotypic expression under varying environmental conditions. Observations during the described experiments suggest that light intensity, light duration, and temperature may be important. Also, plants of BAG vary in severity of expression of the mild reaction and this should be explored. Another need is the identification of closely linked markers, to complement those identified for the Mo-1mo- 1 gene (Irwin et al., 1999). Flanking markers SCAM 11 at $3.2 \mathrm{cM}$ and OPGO 3 at $5.2 \mathrm{cM}$ were reported for the latter. Finally, for applied purposes it is most important to exploit the mild-resistant combination to breed lettuce cultivars with a higher level of resistance than that conferred by the resistance gene alone.
For this last purpose, I have made additional crosses between $M i^{\prime} M i^{\prime} M o-1^{e} M 0-1^{e}$ lines and crisphead cultivars and initiated selection for improved heading type of lines with the high resistance level. Selection, augmented by backcrosses to commercial types, has produced lines with the desired improvement. Additional crosses will be made with romaine, leaf, and butterhead cultivars as well.

\section{Literature Cited}

Bannerot, H., L. Boulidard, J. Marrou, and M. Duteil. 1969. Study of the inheritance of tolerance to lettuce mosaic virus in the variety Gallega de Invierno (in French). Ann. Phytopathol. 1:219-226.

Bjorling, K. 1966. Virus resistance problems in plant breeding. Acta Agr. Scandinavica (Suppl.)16:119-136.

Dinant, S. and H. Lot. 1992. Lettuce mosaic virus: A review. Plant Pathol. 41:528-542.

Grogan, R.G. 1980. Control of lettuce mosaic with virus-free seed. Plant Dis. 64:446-449.

Irwin, S.V., R.V. Kesseli, W. Waycott, E.J. Ryder, J.J. Cho, and R.W. Michelmore. 1999. Identification of PCR-based markers flanking the recessive LMV resistance gene $\mathrm{mol}$ in an intraspecific cross in lettuce. Genome 42:982-986.

Jagger, I.C. 1921. A transmissible mosaic disease of lettuce. J. Agr. Res. 20:737-741.

Robinson, R.W., J.D. McCreight, and E.J. Ryder. 1983. The genes of lettuce and closely related species. Plant Breed. Rev. 1:267-293.

Ryder, E.J. 1970. Inheritance of resistance to common lettuce mosaic. J. Amer. Soc. Hort. Sci. 5:378-379.

Ryder, E.J. 1975. 'Vanguard 75' lettuce. HortScience 14:284-286. 